\title{
DJECA I MLADI IZBJEGLICE U SVAKODNEVICI AUSTRIJSKIH VJEROUČITELJA
}

\author{
Viera Pirker - Jadranka Garmaz
}

\begin{abstract}
UDK: [37.014.12+314.151-054.73-053.5](436)
[27-752-051+ 314.151-054.73-053.5](436)“2015/2016“

Institut für Praktische Theologie

Katholisch-Theologische Fakultät

https://doi.org/10.34075/cs.54.4.5

Pregledni znanstveni rad viera.pirker@univie.ac.at Rad zaprimljen 3/2019.
\end{abstract}

Sveučilište u Splitu, Katolički bogoslovni fakultet

jgarmaz@kbf-st.hr

\section{Sažetak}

U radu se istražuje vjeronauk kao mjesto koje promiče kulturu susreta povećanjem mogućnosti za interkulturalnu razmjenu, informiranje $i$ širenje najboljih praksi integracije. U pet manjih poglavlja podastiru se rezultati religijsko-pedagoškog istraživanja sa Sveučilišta u Beču o ulozi vjeroučitelja u javnim školama s naglaskom na zajednički rad $s$ izbjeglom djecom i mladima. U prvom poglavlju uvodi se u temu $i$ aktualnu teologiju pape Franje o izbjeglicama. U drugom poglavlju predstavlja se projekt Sveučilišta u Beču, a u trećem se sažimlju rezultati. Četurto i peto poglavlje nude nove perspektive glede teme. Prema istraživanju vjeronauk se dokazao kao mjesto ostvarenja dijaloga, zauzimanja za pravdu i dobrobit svakog čovjeka, koje promiče kulturu dijaloga, njeguje kulturu susreta i poboljšava kvalitetu suživota.

Ključne riječi: migracije, vjeronauk, izbjeglice, kultura susreta, interkulturalna razmjena

\section{UvOD}

Iako je položaj vjeronauka u europskim školama različit, ipak iskustvo i pouke stečene $\mathrm{u}$ radu $\mathrm{s}$ izbjeglicama mogu biti korisni za širi europski kontekst. ${ }^{1}$ U Austriji se kao i u Hrvatskoj javlja

Ana Thea Filipović, Religious Education at Schools in Croatia, u: Martin Rothgangel - Martin Jäggle - Thomas Schlag (ur.), Religious Education at Schools in Europe. Part 1: Central Europe, V\&R, Göttingen, 2016., 69-87. Martin Rothgangel - Martin Jäggle - Thomas Schlag, (ur.), Religious Education at schools, u: Europe sv. 1-6 (Wiener Forum für Theologie und Religionswissenschaft; 10), Göttingen, 2012. 
sve više kritičkih glasova protiv vjeronauka u školi i svako malo se traži opravdanje za prisutnost religijske nastave u školi. Zbog toga se vjeronauk mora dokazati u sekularnom, političkom i neutralnom religijskom obrazovnom kontekstu, te su upravo vjeroučitelji oni koji to svakodnevno rade, i to na prvoj crti obrane. I u Austriji ima mnogo vjeroučitelja koji predaju samo taj jedan predmet i po tome ih se može usporediti s hrvatskim prilikama, gdje, osim na Sveučilištu u Zadru, nema dvopredmetnog studija vjeronauka. Pozicija se vjeroučitelja u školi razlikuje od pozicije drugih učitelja. No izazov integracije djece i mladih izbjeglica u školu postavlja se pred cijelu školsku zajednicu. ${ }^{2}$ Imaju li ipak vjeroučitelji u tim pitanjima posebnu ulogu i dublji uvid u školske i vjerske probleme? Priznaje li im škola njihovu specifičnu sposobnost? Kakav je odnos vjeronauka i socijalne zauzetosti u školi? ${ }^{3}$ Koji se društveni diskursi zrcale u procjeni vjeronauka u cjelini?

\section{1. ŽIVJETI I UČITI ZAJEDNO S IZBJEGLICAMA}

Na svijetu ima puno milijuna ljudi koji su u bijegu. Oni traže sigurnost, bolje uvjete za svoju djecu. Većina ih je protjerana iz svoje zemlje, a mnogo je i onih koji traže zaštitu i nov početak u zemljama prihvata. ${ }^{4}$ Mnogi od njih koji su prošle godine došli u Europu ondje će se i integrirati. ${ }^{5}$ Naučiti kako živjeti zajedno s izbjeglicama, središnje je aktualno pitanje za Europu. ${ }^{6}$ Ono je velik politički izazov, koji pokreće ljude u cijeloj Europi, u gradovima, župnim zajednicama, Crkvama, ali posebno u školama. Institut praktične teologije u Beču izložio se tom izazovu u istraživačkom projektu pod vodstvom prof. Regine Polak. Profesorica Polak stručnjakinja je za migracije

2 Priručnik za integraciju djece izbjeglica u školi u Republici Hrvatskoj može se pronaći na www.irh.hr/dokumenti/40-djeca-izbjeglice-u-skolama/file (8. 11. 2019.).

3 O socijalnoj i političkoj ulozi vjeronauka više u: Patrik Dzambo - Jadranka Garmaz - Bernhard Gruemme, Religioese Bildung in Europa. Egzemplarische Einblicke in eine komparative Religionspaedagogik, Lit Verlag, Berlin, 2019. Ana Thea Filipović, Učiti živjeti zajedno. Dimenzije socijalnog učenja u pedagoškoj $i$ teološkoj perspektivi, Kršćanska sadašnjost, Zagreb, 2017.

4 Vgl. http://www.unhcr.org/data.html (23. 10. 2018).

5 U Hrvatskoj postoji integracijska politika izbjeglica. Više o tome na: www.irh.hr/ dokumenti/8-azil-u-hrvatskoj-integracijske-politike/file (10. 10. 2019.).

6 U Hrvatskoj već 25 godina vrlo aktivno djeluje Jesuit Refugee Service- Isusovačka službazaizbjeglice. Više o tom djelovanju nawww. http://www.jrs.hr/ (23. 10. 2018.). 
i religiju na Institutu, ${ }^{7}$ i zajedno s kolegama A. Lehner-Hartmann, V. Pirker i drugima sudjeluje u ovom projektu već nekoliko akademskih godina. ${ }^{8}$

Projekt se uklapa u aktualno poslanje Crkve. Naime, papa Franjo svoj je pontifikat posebno posvetio radu s izbjeglicama. Zauzima se za izbjeglice, bilo da se radi o posjetu otoku Lampedusi, njegovom prvom pastoralnom putovanju izvan Rima, bilo o posjetu izbjegličkim naseljima na Lesbosu i u Idomeniju, bilo o njegovom osobnom angažmanu oko izbjegličkih obitelji, bilo o njegovim pastoralnim i političkim porukama. Papa u svojoj poruci za Svjetski dan izbjeglica i selilaca 2016. kaže: "U ovom povijesnom času, snažno obilježenom velikim migracijama, identitet nije sporedno pitanje. Migranti su prisiljeni promijeniti neke od svojih najosebujnijih obilježja i, htjeli to oni ili ne, to prisiljava na promjenu i one koji ih primaju. Kako te promjene ne doživljavati kao prepreku istinskom razvoju, nego kao priliku za istinski ljudski, društveni i duhovni rast, rast koji poštuje i promiče one vrijednosti koje nas čine još čovječnijima i pomažu nam da živimo uravnotežen odnos s Bogom, drugima i stvaranjem?"9

Papa govori o promjeni na objema stranama. Radi se o promjeni kod onih koji napuštaju svoju domovinu i traže neko drugo mjesto za dom. No potrebna je promjena i kod onih koji prihvaćaju izbjeglice. Cilj je da se dogodi rast u ljudskosti, društvenosti i duhovnosti koji je usmjeren prema specifičnoj vrijednosti: individualizaciji, tj. personalizaciji pojedinca u njegovu odnosu prema Bogu, drugima i cijelom stvorenju. To je zajednička zadaća svih kršćana: raditi na Božjem stvorenju i dati tom radu konkretan oblik.

7 Usp. Regina Polak - Andrea Lehner-Hartmann - Viera Pirker, Migrationskompass: Von Angst bis Zuversicht. Leben und Lernen von mit geflüchteten Menschen, Wien, 2018. Usp. također i www.migrationskompass.eu (23. 10. 2018).

8 U pastoralno-teološkom seminaru studenti su se susreli sa župama koje imaju vlastite projekte s izbjeglicama. Unutar njih postoje krugovi potpore za pojedine obitelji ili župe koje su organizirale naselja za hitna noćenja, u kojima su tisuće ljudi mogle provesti jednu noć ili nekoliko dana; postoje i studentski projekti u kojima se organiziraju tečajevi jezika ili druge forme kraće ili dulje pomoći i skrbi za izbjeglice. U religijsko-pedagoškom seminaru studenti su se obraćali školama te su izbjeglice mogli sudjelovati u nastavi. Proveli su intervjue s vjeroučiteljima katoličke vjere i islama, sudjelovali su na nastavi i razgovarali s učenicima. Rezultati i problematika sabrani su u navedenoj literaturi, a predstavljeni su 24. 5. 2017. godine na Katoličkome bogoslovnom fakultetu Sveučilišta u Splitu tijekom boravka Viere Pirker na Katedri religiozne pedagogije i katehetike u sklopu programa Erasmus.

9 Papa Franjo, Poruka za sujetski dan selilaca i izbjeglica 2016., na: http://w2.vatican.va/content/francesco/de/ messages/migration/documents/papa-francesco_20150912_world-migrants-day-2016.html (23. 10. 2018.). 
Papa Franjo je upozorio i na strukturalne probleme koje sa sobom donose migracijski valovi, što se dobro vidjelo 2015. i 2016. godine: "Migracijski val je strukturalni problem i prvo pitanje koje se pri tome postavlja tiče se prelaska iz faze nužne potrebe na pitanje uspostave programa koji uzimaju u obzir uzroke migracija i uzrokuju promjene te sagledavaju posljedice koje stvaraju novo lice društava i naroda."10

Te se faze $u$ istraživanju jako dobro uočavaju. U Austriji se prva, hitna faza pomoći odvijala u jesen i zimu 2015./2016. godine. U njoj su mnoge institucije i mnogi pojedinci žurno i intenzivno radili. Od ljeta 2016. ta je faza došla do mirnije točke, jer su već bile poduzete organizacijske i konceptualne mjere, a istodobno su i mnoge ulazne rute preko Mađarske i Balkana bile zatvorene ili usporene.

S promjenom vlasti u zimu 2017. uvjeti za izbjeglice u Austriji su se pogoršali, odnosi su postali zategnuti, a politički ton postao je grublji. Mnogi su izbjeglice protjerani s nacionalnih granica u okviru sporazuma Dublin II. ili su deportirani u zemlje podrijetla nakon odbijanja zahtjeva za azil. Drugi pak dobivaju boravišnu dozvolu te mogu planirati dulji boravak. Sve se veća pozornost usmjerava na maloljetnike bez pratnje koji u međuvremenu pristižu. Njima se ograničavaju mogućnosti uspjeha, oni postaju uočljivi izazov, osobito zbog poteškoća i ograničenja školskog rada s izbjeglicama. U njihovoj se specifičnoj situaciji zamjećuje i zrcali problem školskog sustava koji se ne zna nositi ni s djecom koja su rođena u Austriji, jer se migracije kao fenomen ne mogu ograničiti samo na pojam izbjeglištva. Mnoga djeca koja su rođena u Austriji govore njemački kao drugi jezik i imaju enormne poteškoće s usvajanjem rječnika. Školski sustav previše je oslonjen na pretpostavku znanja jezika i inkulturaciju, što u mnogim slučajevima nije ostvarivo. ${ }^{11}$

\section{PROJEKTNI OKVIR}

U ovom ćemo poglavlju ukratko predstaviti kontekst i cilj religijskopedagoškog istraživanja u okviru istraživačkog projekta. ${ }^{12}$

10 Isto.

11 Andrea Lehner-Hartmann - Viera Pirker, Geflüchtete Jugendliche verändern Schule: Eine Untersuchung zu Alltagserfahrungen von Religionslehrerinnen, u: Annegret Reese-Schnitker - Daniel Bertram - Marcel Franzmann (ur.), Migration, Flucht und Vertreibung. Theologische Analyse und religionsunterrichtliche Praxis. Kohlhammer, Stuttgart, 2018., 187-206.

12 Pogledaj mrežnu stranicu projekta: http://pt-ktf.univie.ac.at/forschung/ arbeitsschwerpunkte/ professionalisierung/leben-und-lernen-mit-fluechtlingen/\#c156041 (17. 01. 2018). 


\subsection{Položaj vjeroučitelja $u$ javnim školama}

Škole su ključna mjesta za promatranje procesa društva u cjelini. Teško da postoje ostali prostori u kojima se susreće toliko različitih ljudi - različitog porijekla, političkog mišljenja, stupnja obrazovanja itd. Škole povezuju učenike, ali i njihove obitelji, kao i učitelje, koji se smatraju motorima tih obrazovnih središta. Škola se smatra središnjim mjestom demokratskog obrazovanja. Osim toga, škola djeluje strukturalno na cijelu obitelj. Kada dijete krene u školu, svi se moraju držati određenog tijeka i određenih pravila. Škola djeluje kao središnje mjesto demokratske izobrazbe.

Naš se projektni interes sastoji u tome da što više saznamo o vjeroučiteljima ${ }^{13}$ i njihovoj ulozi u radu s izbjeglicama. Od njih smo htjeli saznati kako su škole organizirale svoj način rada s izbjeglicama, koje su se zamke i izazovi u tome krili, ali i koje su nove mogućnosti i perspektive bile prisutne $u$ tim posebnim okolnostima. Vjeroučitelji se u školama nalaze u posebnoj situaciji, jer je u međuvremenu jak sekularni val u društvu izravno usmjeren protiv vjeronauka u školi. Vjeroučitelji se susreću s kritikom unutar profesorskog kolegija, kritiziraju ih ravnatelji i voditelji kao i sami učenici. No s nastave vjeronauka polaznici se mogu i ispisati. Ponajprije stariji učenici procjenjuju je li nastava dovoljno dobra, je li nastavnik dovoljno simpatičan, jesu li teme dovoljno zanimljive i jesu li njihove ocjene dovoljno dobre. To vodi $\mathrm{k}$ tome da se nastava jako usmjerava prema učeniku: vjeroučitelji daju učenicima na satu dovoljno vremena za njihova osobna pitanja, a u pravilu ocjenjuju s "odličan". Vjeronauk postaje jedan slobodan prostor unutar škole, što ne treba kritički promatrati, jer se vjeronauk i mora sasvim jasno odvijati prema načelu korelacije i usmjerenja na osobu.

U proteklih se 30 godina zbog imigracija dramatično promijenio religiozni krajobraz u Beču. Udio katoličkog stanovništva je sa 78 \% godine 1981. pao na $41 \%$ godine 2011 . U isto vrijeme je skupina od $10 \%$ neopredijeljenih narasla na $30 \%$, dio islamske zajednice skočio je sa $0,4 \%$ na $12 \%$, a Evangelička je crkva pala sa $7 \%$ na $4 \%$. U školama se predaju katolički i islamski vjeronauk, ali i pravoslavni i evangelički. Etika je na mnogim školama alternativni predmet, a postoje nastojanja da se taj predmet uvede kao redoviti za sve učenike.

13 Analiza društvenog angažmana vjeroučitelja dostupna je u sljedećem članku: Josip Periš - Sabina Marunčić, Social engagement of religious education teachers in the archdiocese of Split-Makarska, u: Jadranka Garmaz, Alojzije Čondić (ur.), Challenges to Religious Education in Contemporary Society, Crkva u Svijetu, Split, 2017., 132-148. 


\subsection{Djeca i mladi izbjeglice $u$ austrijskim školama}

Ovaj religijskopedagoški projekt usmjeren je na iskustva vjeroučitelja u javnim školama, i to u školi s izbjeglicama u školskoj godini 2015./2016. Kako škole organiziraju svoje živote s izbjeglicama i adolescentima i s kojim se izazovima i teškoćama susreću? Koje se nove mogućnosti i perspektive mogu otkriti u tom prekidu svakodnevnog školskog života? Posebno se iz istraživanja motivacije vjeroučitelja može bolje razumjeti kako oni djeluju i koju ulogu imaju u kontekstu školskog rada s izbjeglicama.

Da bismo bolje razumjeli kontekst istraživanja, potrebno je skicirati obrazovnu situaciju u Austriji. Naime, u Austriji djeca od 6. do kraja 9. godine školovanja imaju pravo i dužnost školovanja. Isto vrijedi i za pridošle izbjeglice, iako nemaju trajni boravak u Austriji. Čim su prijavljeni, moraju ići u školu (pa čak i ako su na proputovanju). U prvoj, hitnoj fazi pomoći 2015./2016. godine učenici su bili podijeljeni prema najbližim školama, bez pripreme i plana. Školske su zajednice dobile zadaću da tu djecu školuju. Od školske godine 2015./16., do 30. lipnja 2016. ovakvih je učenika bilo 14.233. ${ }^{14} \mathrm{U}$ pravilu se djecu koja su došla bez predznanja najprije prihvaćalo kao "posebnu, izvanrednu djecu", i fokus je bio na učenju jezika. Prema potrebama su organizirani pripremni razredi ili razredi opismenjavanja.

Za mlade je izbjeglice situacija bila teška: ako oni sa 14 ili 15 godina ne bi iz skupine "posebnih" ili "izvanrednih" učenika prešli u skupinu običnih (dakle s potpunom ocjenom i iz njemačkog), tada oni ne bi smjeli nakon 9. razreda više ići u školu. ${ }^{15}$ To je pogodilo 5/6 ili točno 3000 nepripremljenih mladih izbjeglica, koji su primljeni u Austriju samo do svibnja 2016.

Prijelazne mjere sporo se provode i previše je skučen prostor za obrazovanje tih mladih ljudi, ali i za učitelje koji s njima rade. Izbjeglice su se stoga $u$ vrlo kratkom vremenu suočile $s$ rizikom od potpunog gubljenja svoje povezanosti sa zemljom domaćinom i nemaju nikakve mogućnosti obrazovanja i osposobljavanja.

I u Hrvatskoj djeca izbjeglice imaju pravo na pohađanje škola, no nažalost nisu nam dostupni statistički podatci o stvarnome stanju. U Hrvatskoj međutim ima mnogo manje izbjeglica koji ondje zbilja žele i ostati. Proteklih je godina oko 650.000 ljudi prošlo kroz Hrvatsku kao tranzicijsku zemlju, u nadi da će ih primiti Njemačka,

14 Usp. Bundesministerium für Bildung, Flüchtlingskinder und jugendliche an österreichischen Schulen. Beilage zum Rundschreiben Nr. 15/2016., September 2016., https://www.bmb.gv.at/ministerium/rs/2016_15_beilage.pdf (20. 05. 2017.).

15 Isto, 12-13. 
skandinavske zemlje, Austrija. ${ }^{16}$ No od godine 2016. se i u Hrvatskoj zaprimaju zahtjevi za azil te se ona kao članica EU obvezala na kvotu koju će primiti, premda je gospodarsko stanje za sve teško i premda mladi u Hrvatskoj ni sami ne nalaze posao i sve su veće socijalne razlike. U Hrvatskoj su iskustva s traumom izbjeglištva i progonstva u Domovinskom ratu 1990-ih godina vrlo svježa u narodu, što s Austrijom nije slučaj. Na toj posebnoj osjetljivosti za izbjeglice u Hrvatskoj može se graditi i posebna senzibilnost za sve protjerane i raseljene narode. ${ }^{17}$

\subsection{Znanstveno istraživanje}

Istraživački projekt koji se provodi slijedi načelo da su podučavanje i istraživanje na Sveučilištu u Beču usko povezani. U ovom projektu istraživanje usmjereno na podučavanje znači da su studenti izravno uključeni u razvoj i prikupljanje podataka o istraživanju te mogu aktivno oblikovati proces istraživanja sa svojim pitanjima i interesima. U sklopu dva seminara u akademskoj godini 2016./17. učenici su na terenu bili istraživači, morali su poznavati projekte, provoditi intervjue i razvijati teze.

U pastoralnoteološkom seminaru studenti su se bavili župnim zajednicama i organizacijama koje imaju vlastite izbjegličke projekte. Među njima su bili pomoćni krugovi za pojedinačne obitelji, zajednica koja je postavila hitne spavaonice gdje bi mnogo tisuća ljudi moglo ostati jednu noć ili nekoliko dana i sl. Među njima su djelovali studenti koji organiziraju podučavanje njemačkog jezika i druge oblike kratkoročne i dugoročne pratnje. U religijskopedagoškom djelokrugu pomoći polaznici su se okrenuli školama u kojima se podučavaju djeca i adolescenti izbjeglice. Intervjuirali su vjeroučitelje katoličkoga i islamskog vjeronauka, nazočili su nastavi u razredima i razgovarali sa studentima i nastavnicima. Cjelokupno znanstveno istraživanje u seminaru odvijalo se u nekoliko faza.

Najprije su studenti analizirali svoje "subjektivne teorije" o izbjeglicama. To je metoda po kojoj se sakupe unutarnje slike i pret-

16 Usp. Tajana Sisgoreo, Refugee Crisis in Croatia - Report, na: www.borderline-europe.de; također vidi https://www.borderline-europe.de/sites/default/files/ background/Refugee\% 20Crisis\%20in\%20Croatia\%20 Report.pdf (17. 01. 2018).

17 Isusovac Tvrtko Barun (Isusovačka služba za izbjeglice) na međunarodnom simpoziju KBF-a u Splitu govorio je o temi "Iskustvo Isusovačke službe za izbjeglice u promicanju i življenju katoličkog socijalnog nauka u Hrvatskoj”. Pitanje brige o izbjeglicama on povezuje s promicanjem pravde i brige za pravdu koja ostvaruje vjeru. Usp. http://www.kbf.unist.hr/images/2019-20/KBFST-Simpozij25_knjizica_sazetaka-v-1-1.pdf. 
postavke i sistematiziraju se putem razgovora. ${ }^{18} \mathrm{Na}$ osnovi rezultata subjektivnih teorija kao i analize značajne literature razvili smo naputke za razgovore s učiteljima. Te su razgovore studenti sami proveli, transkribirali ih i analizirali. Rezultati su bili prikazani učiteljima. Učitelji su se na to osvrnuli metodom rasprave $u$ skupini, koja je također bila transkribirana i interpretirana. Cjelokupni je projekt utemeljen kvalitativno empirijski, tako da je vrednovanje interpretativno-analitičko. ${ }^{19}$ Razgovori su vođeni sa tri katolička vjeroučitelja i dva muslimanska. Razgovori su provedeni, prepisani i analizirani od strane samih studenata. Dobiveni rezultati predstavljeni su nastavnicima koji su bili uključeni, koji su tada imali skupnu raspravu o svojim iskustvima i uvidima. I ta je rasprava prepisana $\mathrm{i}$ interpretirana. Četiri učitelja bila su uključena u skupnu raspravu, koja čini najvažniju osnovu za rezultate $\mathrm{u}$ nastavku. ${ }^{20}$

\section{ZAKLJUČCI O POJEDINAČNIM TEMAMA}

Učitelji vjeronauka uključeni u podučavanje u različitim srednjim školama imaju vrlo različita iskustva. Postaje jasno i u pojedinačnim razgovorima i u skupnoj raspravi da je teško govoriti "o izbjeglicama u školi”, budući da su uvjeti i iskustva u različitim školama potpuno različiti. Dok su djeca i mladi izbjeglice u jednoj školi

18 Usp. Andrea Lehner-Hartmann, Religiöses Lernen. Subjektive Theorien von ReligionslehrerInnen, Kohlhammer, Stuttgart 2014., u nizu Praktische Theologie heute, 133.

19 Usp. Meuser Michael - Ulrike Nagel, Experteninterviews-wissenssoziologische Voraussetzungen und methodische Durchführung, u: Barbara Friebertshäuser - Heike Boller - Sophia Richter (prir.), Handbuch qualitative Forschungsmethoden in der Erziehungswissenschaft, Weinheim, 2010., 457-471.

20 Andrea Lehner-Hartmann, Religiöses Lernen. Subjektive Theorien von ReligionslehrerInnen, Kohlhammer, Stuttgart 2014., (Praktische Theologie heute, 133). "Subjektivna teorija" istraživački je pristup. Osoba izražava svoje mišljenje o određenoj temi, druga osoba pokušava to izražavanje urediti u strukturiranu argumentaciju. Prva osoba ponovno analizira tu strukturu, da vidi slaže li se ona s njom. Subjektivne teorije pojašnjavaju koje pretpostavke, predrasude ili općeniti diskursi prožimaju jedno mišljenje, tj. stav. Uputili smo studente da formuliraju svoju subjektivnu teoriju o slici izbjeglica i da o njoj razgovaraju. Subjektivne su teorije u seminaru pokazale da je većina studenata pod utjecajem dvaju diskursa. Prvi je medijski diskurs, koji prožima javnu sliku o izbjeglicama, bijegu i progonstvu te integraciji. Drugi diskurs temelji se na osobnim susretima i iskustvima kao i kršćanskoj slici o čovjeku, koja osnažuje osobu i vrijednost pojedinca. Studenti su ustvrdili sljedeće o razgovoru o vlastitim subjektivnim teorijama:

“... čini te osjetljivim prema mišljenju drugih.

... upućuje te na veću pozornost prema institucijskim i strukturalnim aspektima.

... omogućuje ti bolje razumijevanje učinka vlastitih riječi.

...prijekoje potrebandabi tepripremiona teme u školipremakojima gajiš predrasude.” 
vrlo neupadljivo integrirani u razrede, u drugim su školama najprije organizirani prijelazni razredi u kojima vjeroučitelji također predaju i pripremaju ih za punu integraciju. Nadalje, kada učitelji govore o svojim različitim iskustvima, postaje jasno da oni nisu uključeni u odluke, da su informacije kratkoročne, da sami imaju vrlo malo uvida u putove i mogućnosti izobrazbe djece izbjeglica. Na temelju skupnog razgovora učitelji su došli do uvida koje ćemo predstaviti u četiri tematske cjeline: Jezik i komunikacija; Zajednički život i predrasude; Religija, Vjeroučitelj u nastavničkom kolegiju.

\subsection{Jezik i komunikacija}

U području jezika i komunikacije želimo pojasniti sljedeće: Svi učitelji napominju kao je veoma važno da djeca izbjeglice trebaju učiti njemački. Ta se tvrdnja slaže s dominantnom javnom raspravom. Komunikaciju učitelji shvaćaju puno više od pukog razumijevanja jezika.

Putem komunikacije, osobito u skupini učenika, izbjeglice osjećaju pripadnost, priznanje i mogu razviti osjećaj pripadnosti. Iz tog je razloga za izbjeglu djecu lakše doći u Austriju ako mogu posjećivati redovitu nastavu. To se u osnovnoj školi može vrlo brzo postići. Ipak, komunikacija među učenicima ne odvija se sama od sebe: neizbježno je posredovanje nastavnika, osobito kada se radi o komunikaciji između dječaka i djevojčica.

Da bismo to mogli bolje razumjeti, donosimo iskustvo vjeroučitelja Franka o jednom izletu:

"Djeca su već međusobno razgovarala, ali je bilo nemoguće da uspostave međusobni kontakt. Na to nisu navikli. Ali uvijek kad bismo moderirali susret, kad bismo rekli da igramo igru loptom na način da kad netko dobije loptu smije postaviti pitanje, tada bi djeca postavljala puno pitanja. Ali ako nismo moderirali i tako ostvarivali kontakt, teško je među dječacima i djevojčicama bilo uspostaviti kontakt” (GD_Frank_741-747).

Tek razigrano moderiranje nastavnika može omogućiti međusobni kontakt učenika. Jasno je da međusobni interes postoji, ali ne znaju kako uspostaviti međusobne kontakte. Također postoje predrasude da pridošlice ne poznaju proces uspostave jednostavnih kontakata među djevojčicama i dječacima.

\subsection{Zajednički život i predrasude}

U području zajedničkog života i predrasuda došli smo do sljedećih zaključaka. Važan je osobni kontakt s izbjeglicama: oni nakon toga više nisu apstraktne, već konkretne osobe. Intenzivnija komu- 
nikacija među izbjeglicama i austrijskim učenicima pojačava osjećaj dobrodošlice. Za izbjeglice koji govore arapski olakšavajuća je okolnost ako mogu s islamskim vjeroučiteljem govoriti materinskim jezikom. Upravo su muslimanski vjeroučitelji pomogli sagraditi mostove između roditelja i učitelja: oni su prevodili nastavne materijale, pisma i pozive, sudjelovali na roditeljskim sastancima i sl. Učitelji koji i sami dijele iskustvo preseljenja, mogu lakše razumjeti izbjeglu djecu. Oni i među kolegijem učitelja uživaju osobito poštovanje.

Učitelji izvještavaju kako dvojezični austrijski polaznici također podupiru pridošlice prevoditeljskim uslugama. No i oni sami mogu lako doći do granica prekomjernog naprezanja, ako teško slijede nastavni materijal ili kada se suočavaju s dramatičnim izbjegličkim iskustvima.

\subsection{Religija}

Projekt je na temu religije došao do sljedećih rezultata: Religija se upravo kroz problem izbjeglica shvaća kao ambivalentan faktor. $\mathrm{S}$ jedne strane izbjeglice imaju mogućnost osloboditi se religije i njezinog podčinjavanja (npr. u Afganistanu), a s druge je strane doživljavaju kao značajan element svojega identiteta. Religija i kultura su u sasvim drugačijem položaju u zemlji iz koje oni dolaze; ovdje je potrebno izbjeglice o tome educirati.

Muslimanski učitelji naglašavaju važnost predstavljanja terorizma, nasilja i mržnje prema židovima i kršćanima kao apsolutno neprihvatljivima za islam. Kršćanski vjeroučitelji naglašavaju da je $\mathrm{u}$ Austriji religija privatna stvar i da ne postoji nužna povezanost $\mathrm{s}$ religioznom praksom ili vjeroispoviješću. Solidarnost se smatra zajedničkim dobrom kršćanske i islamske religije kao i sekularnog društva.

Primjer iz nastave: Katarina je sa svojim afganistanskim učenicima radila na tome da odgonetne po čemu se prepoznaje religija u društvu. U pozadini toga se nalazi rasprava o marami koja već nekoliko godina vlada javnom sferom. Je li marama na glavi muslimanskih žena znak slobodnog izražavanja religije ili ona ukazuje na patrijarhalno podčinjavanje žene?

Katarina je ispitivala svoje učenike iz Afganistana o religioznim simbolima. Njima uopće nije palo na pamet da bi marama bila znak religioznosti, ona je po njihovu mišljenju dio kulture i tradicije.

Katarina: "Dugo mi je trebalo da shvatim kako je marama na glavi muslimanki znak religijske pripadnosti. Ja sam mislila da je to vanjština, jer je to za nas samo vanjština, ali za njih je vanjsko pokazivanje religioznosti, kulture i tradicije samo po sebi razumljivo, i oni o tome gotovo i ne promišljaju" (GD Katarina). 
Također treba kazati da je izbjeglicama teško prihvatiti činjenicu da žene u Austriji ne nose maramu na glavi, nego kosu slobodno pokazuju. Na to se još moraju priviknuti.

Muslimanska vjeroučiteljica Sofija pripovijeda o nejasnoći između religije i kulture: "Njima treba vremena da se na to priviknu. No mislim da to pitanje uopće nema veze s religijom. Ima puno veze s tradicijom, jer ni oni ne znaju puno o religiji, bar ja tako osjećam" (GD Sofia 679-692).

Zanimljivo je da se "navikavanje" na žene s nepokrivenom kosom koristi od strane učitelja kao pokazatelj uspješne integracije $\mathrm{u}$ austrijsko društvo. ${ }^{21}$

\subsection{Vjeroučitelj u nastavničkom kolegiju}

Zanimala nas je uloga vjeroučitelja u kolektivu i školi. Došli smo do sljedećih rezultata:

Škola je društveni pokretač: ona prati događaje solidarnosti, prikuplja novac, radi zajedno s društvom. U školi je samo po sebi razumljivo da se vjeroučitelji angažiraju u radu s izbjeglicama. Od drugih se učitelja to ne očekuje koliko s očekuje od njih. Religija se u školi sve više razumijeva kao etičko-moralni čuvar i ima ulogu vrijednosne orijentacije, ali nije shvaćena kao religija. Škola reducira religiju na društveni angažman. Vjeroučitelji su animirali svoje učenike na rad s izbjeglicama putem društveno korisnog učenja. Društveno učenje ostalo je nastavni projekt, npr. u jezičnim tandemima na vjeronauku ili prilikom prikupljanja pomoći za jednu izbjegličku obitelj i sl.

\subsection{Razvoj škole kroz zajednički angažman}

Vjeroučitelji se nerijetko nalaze na rubu radnog kolektiva. Njihov predmet se ne shvaća ozbiljno u kontekstu različitih predmeta, ne samo zato što učenici mogu slobodno izabrati hoće li pohađati nastavu vjeronauka. Osim toga, nastava vjeronauka često je u rasporedu stavljena na kraj školskih sati ili se odvija poslije podne, a učitelji su zaposleni u nekoliko škola i nisu u cijelosti dio nastavničkog tima ni u jednoj školi. Nedostatak svijesti o značenju vjeronauka prenosi se i na vjeroučitelje. U isti mah oni imaju posebno oko za oblikovanje koegzistencije i školske kulture. Oni također vide svoj zadatak kao aktivno oblikovanje škole kao životnog prostora za učitelje, učenike i druge subjekte obrazovanja.

21 Usp. Andrea Lehner-Hartmann - Viera Pirker, Die Bedeutung von Religion in der Arbeit mit geflüchteten SchülerInnen, Österreichische Religionspädagogische Forum, 26 (2018.) 1, 46-60, 53-54. 
Učenik Frank kaže: "Ja bih rekao da su kod nas izbjeglice pridonijele razvoju škole, jer smo mi imali kontakte s drugim učiteljima, s kojima inače nikada ne bismo stupili u kontakt. I mislim da smo sklopili prijateljstva, da smo imali puno posla s drugim sadržajima, s kojima se inače nikada ne bismo upoznali. Utoliko je to bila jedna vrsta dara" (GD Frank 452-457).

Učitelji kazuju da je zajednički angažman, zajednički rad u izvanrednoj situaciji u šk. god. 2015./2016. pridonio razvoju kolektiva. Frank smatra darom to što su izbjeglice došle u njihovu školu. Zahvaljujući njihovu dolasku, mnogi su kolege stupili u kontakt jedan s drugim, a škola se nanovo ujedinila oko jedne teme ili problema.

\section{VJEROUČITELJI U ŠKOLI}

Na osnovi analize skupne rasprave i pojedinačnih intervjua mogu se donijeti neki sveobuhvatni uvidi: Učitelji koji rade s mladim izbjeglicama trebaju potporu u svojem promišljanju o tome što religija znači u životima izbjeglica i mladih ljudi. U tom okviru učitelji trebaju posjedovati izraženije kompetencije u međureligijskom dijalogu, kako u teoretskom tako i u svakodnevnom praktičnom radu. Kao graditelji mostova između jezika, religija i kultura, oni trebaju stručnost, nadzor i pratnju, kao i slobodu da ne moraju uvijek biti prevoditelji u jezičnom ili kulturnom smislu.

Škola je društveno i javno mjesto, za razliku od obitelji, koja je privatni prostor. Stoga je škola važno mjesto društvenog obrazovanja i razvoja. Škola se mora ozbiljno shvatiti kao zajednički životni prostor učenja i suživota te oblikovati u skladu sa svima koji su uključeni u proces obrazovanja.

Vjeroučitelji su višestruko angažirani: ne samo što rade u učionici nego prate atmosferu u školi, razvoj škole, susrete među ljudima u školi. Vjeroučitelji u školi mogu aktivno sudjelovati u oblikovanju društva i, iz perspektive svoje religije, raditi kako bi osigurali da ovaj svijet ima veći udio u Božjem stvaranju. Škole prihvaćaju izazove koje nam svijet trenutno daje.

Kao članovi kršćanske zajednice, Crkve, i navjestitelji kršćanske poruke, vjeroučitelji su na strani ljudi koji žive u siromaštvu, bijedi i ugnjetavanju. Trebaju im stati uz rame, a kao učitelji vjere moraju se zapitati kako mogu naučiti učenike evanđeoskom milosrđu u ovom svijetu, takvom kakav jest, i uvijek gledati na svijet kakav bi trebao biti i koji oni zajedno sa svojim vjeroučenicima mogu učiniti mjestom nade. ${ }^{22}$

22 Andrea Lehner-Hartmann - Viera Pirker, Living with and learning from refugees. Schools in Vienna dealing with global challenges, u: Helmut Kury - Slawomir 


\section{Perspektiva}

Nakon takozvane "migracijske jeseni" 2015. imigracija u Austriji opet je naglo pala. S jedne strane znatno je manje novih izbjeglica $\mathrm{u}$ austrijskom školskom sustavu, a drugi su već integrirani u središnji školski sustav. S druge strane, i jedni i drugi se moraju boriti s učincima trauma i drugih izazova koje donosi svaka migracija.

Problem mladih ljudi koji se nisu integrirali u školski sustav na vrijeme, više ne utječe izravno na škole, jednostavno zato što one nisu odgovorne za te mlade ljude. Umjesto toga, to je problem cijelog društva. Jedva da postoji obrazovanje za te mlade ljude, oni se već smatraju izgubljenom naraštajem, uskraćenim za bilo kakvu integraciju, a osobito onu u svijet zaposlenih ljudi. Psihodruštvene posljedice teško su predvidive i uglavnom su društveno skrivene. Uz to, mjere za povratak u prve zemlje prihvata iz preporuke Dublin II. aktivno se provode na razini države, tako da se djeca i mladi koji su se već djelomično integrirali u Austriji opet mogu istrgnuti iz svojega novog društvenog okruženja.

\section{ZAKLJUČAK}

Imigracije su izazov kako za vjeronauk, tako i za cijeli društveni i obrazovni sustav. ${ }^{23} \mathrm{U}$ tom kontekstu sve je značajnije dodatno istraživanje te teme, njezino produbljivanje i priopćavanje rezultata istraživačkih projekata. U ovom radu predstavljeni su kratki uvidi $\mathrm{u}$ istraživanje koje može $\mathrm{u}$ budućnosti biti od pomoći i drugim zemljama. Rezultati istraživanja dostupni su u Kompasu za migracije, ${ }^{24}$ kao radni materijal usmjeren na praksu. Osobe koje profesionalno i volonterski prihvaćaju migracije kao značajne, pozitivne izazove za Europu mogu koristiti Kompas za samostalno rad, čak i u kontekstu

Redo (ur.), Refugees and Migrants in Law and Policy. Challenges and Opportunities for Global Civic Education, Springer, New York - Heidelberg, 2018., 235-260.

23 Na Katoličkom bogoslovnom fakultetu u Splitu od 2015. godine organizira se međunarodni seminar iz Interakcije usmjerene na temu, prema Ruth Cohn, kao edukacija iz nastavničkih kompetencija visokoškolskih nastavnika, vjeroučitelja, ali i drugih socijalnih djelatnika radi usvajanja socijalne kompetencije i jačanja političke svijesti i odgovornosti. Više o tome u: Jadranka Garmaz, Living learning in higher education: myth or reality? Theme-Centered Interaction (TCI) at the Catolic Faculty of Theology in Split, u: Patrik Dzambo - Jadranka Garmaz Bernhard Gruemme (ur.), Religioese Bildung in Europa.Exemplarische Einblicke in eine komparative Religionspaedagogik, LIT, Muenster, 2019., 12-19.

24 Regina Polak - Andrea Lehner-Hartmann - Viera Pirker, Migrationskompass: Von Angst bis Zuversicht. Leben und Lernen von mit geflüchteten Menschen, Wien, 2018. Usp. također www.migrationskompass.eu (23. 10. 2018.). 
politički napetih situacija. Taj se materijal promišlja i nadopunjuje te se i dalje razvija. Ljudi koji moraju bježati, često se nalaze u posebno izazovnim i pravno nejasnim životnim situacijama. No nikako se ne bi smjelo zaboraviti: bijeg je samo jedan od mnogih oblika migracije. Njezina su lica različita, ali stav Crkve vrlo je jasan. Potrebno je, kako kaže papa Franjo, "primiti, zaštititi, promicati i integrirati migrante i izbjeglice" 25 na vjeronaučnoj nastavi, u školama, župnim zajednicama, ali još više i na društvenoj i socijalnoj razini zauzeti stav iskrene solidarnosti i pravde prema svima, kako bi se jačala kulturna razmjena i integritet društva sa svim njegovim različitostima.

\section{CHILDREN AND YOUNG REFUGEES IN THE EVERYDAY LIFE OF AUSTRIAN CATECHISTS}

\section{Summary}

The paper explores religious education as a place that promotes the culture of encounter by enhancing opportunities for intercultural exchange, information and dissemination of the best practices of integration. The five smaller chapters present the results of a religious-pedagogical study from the University of Vienna on the role of catechists in public schools, with an emphasis on working together with refugee children and young people. The first chapter introduces the theme and current theology of Pope Francis on refugees. The second chapter presents the project of the University of Vienna, and the third summarizes the results. The fourth and fifth chapters offer new perspectives regarding the topic. According to the research, religious education has proved itself to be a place for dialogue, advocacy for justice and the well-being of every person, a place that promotes the culture of dialogue, nurtures the culture of encounter and improves the quality of coexistence.

Keywords: migration, religious education, refugees, culture of encounter, intercultural exchange

\footnotetext{
25 Poruka pape Franje za Svjetski dan selilaca i izbjeglica 2018., http://w2.vatican.va/content/francesco/de/messages/migration/documents/papa-francesco_20170815_world-migrants-day-2018.html (14. 1. 2018.).
} 